\title{
The relationship between sleep quality, depression, and anxiety in patients with epilepsy and suicidal ideation
}

\author{
A relação entre qualidade de sono, depressão e ansiedade em pacientes com epilepsia e \\ ideação suicida
}

Cristina Maria Duarte Wigg ${ }^{1,2}$, Alberto Filgueiras ${ }^{3,4}$, Marleide da Mota Gomes ${ }^{5}$

\begin{abstract}
The relationships among suicidal ideation, sleep, depression, anxiety, and effects on epilepsy require more research. Objective: The aim of this study was to estimate the prevalence of suicidal ideation in outpatients with epilepsy, and relate this to sleep quality, daytime sleepiness, depression, and anxiety. Method: Ninety-eight non-selected patients were evaluated. The subjects were classified as "suicidal ideators" or "non-ideators", based on their response to item 9 of the Beck Depression Inventory. Results: The prevalence of suicidal ideation was $13.3 \%\left(\chi^{2}=50.46, p<0.001\right)$. The differences between cases with or without suicidal ideation were statistically significant in relation to sleep quality $(p=0.005)$ and symptoms of depression $(p=0.001)$ and anxiety $(p=0.002)$. Conclusion: Our results revealed that depression and anxiety were associated with sleep quality, daytime sleepiness, and suicidal ideation and that depression and sleep disturbance were good predictors of suicide in subjects with epilepsy.
\end{abstract}

Keywords: epilepsy, suicidal ideation, depression, anxiety, sleep disorders, sleep quality, predictors.

RESUMO

A relação entre ideação suicida, sono, depressão e ansiedade, bem como as implicações da epilepsia nessa relação ainda exigem mais pesquisa. Objetivo: Estimar a prevalência de ideação suicida em pacientes ambulatoriais com epilepsia e relacioná-la com qualidade do sono, sonolência diurna, depressão e ansiedade. Método: Foram avaliados 98 pacientes não-selecionados. Os indivíduos foram classificados como tendo ou não ideação suicida, com base nas respostas ao item 9 do Inventário Beck de Depressão. Resultados: A prevalência de ideação suicida foi de $13,3 \%\left(\chi^{2}=50,46 ; p<0,001\right)$. As diferenças entre os casos com e sem ideação suicida foram estatisticamente significativas em relação à qualidade do sono $(p=0,005)$, sintomas depressivos $(p=0,001)$ e ansiosos $(p=0,002)$. Conclusão: Depressão e ansiedade mostraram associação com qualidade do sono, sonolência diurna e ideação suicida; depressão e distúrbios do sono foram bons preditores de suicídio em epilepsia.

Palavras-chave: epilepsia, ideação suicida, depressão, ansiedade, distúrbios do sono, qualidade do sono, preditores.

Suicide and overall mortality are higher in patients with epilepsy (PWE) than in the general population. We must be cautious in the study of comorbidity. Prevalence rates of psychiatric comorbidities require more studies and more appropriate therapeutic ${ }^{1,2,3,4,5,6,7,8,9}$. However, knowledge concerning suicide and its ideation in PWE is still limited. Some authors have reported specific risk factors for suicide in epilepsy ${ }^{8}$, such as patients being relatively young (25-49 years), male sex, early onset of epilepsy, temporal lobe seizures, the presence of brain injuries, difficulty in controlling epileptic seizure episodes, and psychosocial and occupational difficulties ${ }^{3}$. Another important association is related to suicidal thoughts, behavior, and sleep disorders. The study of this association has advanced in recent years,

1'Departamento de Psicometria, Instituto de Psicologia, Universidade Federal do Rio de Janeiro, Rio de Janeiro RJ, Brazil; ${ }^{2}$ Seção de Neuropsicologia, Instituto de Psicologia, Universidade Federal do Rio de Janeiro, Rio de Janeiro RJ, Brazil;

${ }^{3}$ Laboratório de Análise de Dados, Núcleo de Neuropsicologia Clínica e Experimental, Pontifícia Universidade Católica do Rio de Janeiro, Rio de Janeiro RJ, Brazil;

${ }^{4}$ Communication Science and Disorders, Department of Health Sciences, University of Western Ontario, London ON, Canada;

${ }^{5}$ Faculdade de Medicina, Programa de Epilepsia, Instituto de Neurologia, Universidade Federal do Rio de Janeiro, Rio de Janeiro RJ, Brazil.

Correspondence: Cristina Maria Duarte Wigg; Setor de Neuropsicologia, Instituto de Neurologia Deolindo Couto, Universidade Federal do Rio de Janeiro; Av. Venceslau Braz, 95; 22290-140 Rio de Janeiro RJ, Brasil; E-mail: cristina.wigg@gmail.com

Conflict of interest: There is no conflict of interest to declare.

Received 31 October 2012; Received in final form 06 January 2014; Accepted 28 January 2014 
and the results have demonstrated that suicidal ideation and behavior are closely associated with sleep disorders, such as insomnia, nightmares, daytime sleepiness, and difficulty initiating and maintaining sleep ${ }^{10,11,12,13,14}$. Furthermore, suicidal individuals demonstrate increased frequency and severity of several sleep disorders compared to non-suicidal individuals ${ }^{15}$. Although epilepsy is often associated with sleep and mood disorders and suicidal ideations, no studies could be found regarding this correlation in PWE. Research has demonstrated that many variables may contribute to the prevalence of suicidal ideation and the imminent risk of suicide in epileptic patients; therefore, studies are needed to clarify the relationships among suicidal feelings, sleep quality, and symptoms of depression and anxiety to prevent psychological distress and minimize suicide risk in such patients. Consequently, there is limited knowledge concerning suicide and its ideation in PWE. The present study was a preliminary investigation into the association between suicidal ideation and other variables, such as sleep quality, daytime sleepiness, and depression and anxiety in a nonselected sample population of PWE consecutively attending an outpatient epilepsy care facility.

\section{METHOD}

\section{Study design and participants}

This was a cross-sectional study that was approved by local ethical committee and included 98 non-selected adult PWE from the outpatient clinic of the Neurological Institute, Universidade Federal do Rio de Janeiro, Rio de Janeiro, Brazil. The patients were men and women, at least 18 years of age, who were diagnosed with epilepsy (focal or generalized) according to International League Against Epilepsy criteria. Only patients on a stable antiepileptic drug (AEDs) regimen (i.e. no changes over the last 4 weeks) were included. Patients with other active neurological diseases were excluded.

\section{Procedures and instruments}

The participants were classified as and divided into "suicidal ideators" or "non-ideators" based on their responses to item 9 of the Beck Depression Inventory (BDI), which is considered a quick and effective measure of suicidal ideation ${ }^{6}$. Each subject completed a clinical questionnaire, a demographic questionnaire, the Beck Anxiety Inventory (BAI) and BDI, the Pittsburgh Sleep Quality Index (PSQI), and the Epworth Sleepiness Scale (ESS). The PSQI ${ }^{16}$ includes 19 questions that are combined to form 7 components: (1) sleep quality - individual perceptions about the quality of sleep; (2) sleep latency - time required to begin sleep; (3) sleep duration - duration of sleep or how long the individual stays asleep; (4) habitual sleep efficiency - the relationship between the number of hours slept and the number of hours remaining in bed (not necessarily asleep); (5) sleep disturbance - the presence of situations that compromise sleep hours; (6) sleep medication - analyses the use of sleep medication, and (7) daytime dysfunction - disturbances and sleepiness during the day, referring to changes in disposition for the performance of routine activities. Each component is scored from 0 to 3 . The seven components combined form a global score that ranges from 0 to 21 , where 0 indicates no difficulty and 21 indicates severe difficulty. A global score $\geq 5$ distinguishes "bad" from "good" sleepers ${ }^{16}$. Depression symptoms for the previous week were evaluated by the $\mathrm{BDI}^{17}$. Depression was defined by a score $\geq 12$, where: 12 19, 20-35, and 36-63 indicate mild, moderate, and severe depression, respectively ${ }^{17}$. The BDI Total Score without item 9 (suicide) was used to provide a measurement of depression severity uninfluenced by suicidal ideation ${ }^{18}$. Anxiety symptoms for the previous week were evaluated by the $\mathrm{BAI}^{17}$. Anxiety was defined by a score $\geq 10$ where: 10-16, 17-29, and 30-63 indicate mild, moderate, and severe anxiety, respectively $^{17}$. Item 9 of the BDI (suicide) provides an index of suicidal ideation within the previous week. This item ranges from 0 to 3 ( $0=\mathrm{I}$ don't have any thoughts of killing myself; $1=\mathrm{I}$ have thoughts of killing myself, but I would not carry them out; $2=\mathrm{I}$ would like to kill myself; $3=\mathrm{I}$ would kill myself if I had the chance). BDI item 9 has been used in other studies ${ }^{18,19}$ to provide an index of suicidal ideation. A score of 1 indicates passive suicidal ideation (no intent), and a score of 2 or 3 indicates active suicidal ideation, with desire or intent ${ }^{18}$. Finally, daytime sleepiness was measured by the ESS ${ }^{20}$. The ESS is an eight-item Likert-type scale with four discrimination categories: 0 is "would never doze", 1 is "slight chance of dozing", 2 is "moderate chance of dozing", and 3 is "high chance of dozing". The instrument was constructed from observations about the nature and occurrence of daytime sleepiness and sleep. The total score ranged from 0 , no sleepiness, to 24 , high sleepiness. The applied instruments have already been adapted and standardized for use in the Brazilian population.

\section{Statistical analysis}

Descriptive statistics for these groups were also obtained by the number of cases and frequencies (\%), divided in both groups by the variables gender, age (under or over 40 years old), seizure frequency (fewer or more than six epileptic attacks per year), number of AEDs taken by the patient (mono- or polytherapy), depression (total BDI score less or greater than 12) and anxiety (total BAI score less or greater than 10). The mean (M) and standard deviation (SD) were calculated for age, seizure frequency, number of AEDs taken by the patient, the total ESS score, all 7 components and the global severity of the PSQI, and the total scores from the BAI and BDI. We used independent-samples Mann-Whitney-Wilcoxon 
tests to compare "suicidal ideators" and "non-ideators" for each variable. The main purpose of the present statistical analysis was to understand the capability of each of these six variables in predicting suicidal ideation. To this end, we used a discriminant analysis using the groups defined by item 9 of the BDI criterion previously describe by Smith et al. ${ }^{18}$. The discriminant function ${ }^{21}$ extracts a minimum reason between the multivariated pairs of means and the variance from the covariance matrix. The significance of the hypothesis test shows the probability of a random person chosen from the previously defined groups being a part of one or the other group. Fisher's analysis of variance (ANOVA) test was used for this purpose. The discriminant index $(\lambda)$ is used to calculate the intersection point between the distributions of the established groups within each measured variable. Finally, the standardized coefficient suggests the amount of covariance not explained by the variable. A good variable, despite the size of the explained covariance, should be differently distributed between the pre-defined groups showing a significance (p-value) $<0.05$ in the hypothesis test ${ }^{21}$. However, it is desirable to obtain a good discriminant index $<0.60$. All data were analyzed using Statistical Package for the Social Sciences Version 18.

\section{RESULTS}

The 98 participants had a mean age of 39.7 years old $(\mathrm{SD}=12.3)$, with an average seizure frequency per year of 16.9 ( $\mathrm{SD}=55.1)$. The average number of AEDs taken by the patients was $1.6(\mathrm{SD}=0.7)$. Table 1 depicts the number of each variable and its distribution (in percentages) within suicidal ideators $(\mathrm{N}=13, \%=13.3 \%)$ and non-ideators $(\mathrm{N}=85$, $\%=86.7 \%$ ) for gender, age, seizure frequency, number of AEDs taken by the patient, depression and anxiety, respecting the previously established criteria.

Table 2 presents the descriptive statistics and MannWhitney-Wilcoxon U-test results for independent samples results according to the proposed methodology. Demographic variables, including age, frequency of seizures, and number of AEDs, did not show significant differences $(\mathrm{p}>0.05)$. Also, sleepiness was not significantly different between the two groups when measured by ESS. Regarding sleep quality, the PSQI measures eight aspects of this construct; however, just three of them showed significant differences: sleep quality, sleep disturbances, and global score. Sleep latency, sleep duration, habitual sleep efficiency, use of sleep medication, and diurnal dysfunction were not significantly different between the two groups; therefore, the global score for sleep quality was likely significantly different because of the scores for sleep quality and sleep disturbances. Finally, anxiety (measured by BAI) and
Table 1. Descriptive relationship between suicidal ideation and other variables.

\begin{tabular}{|c|c|c|}
\hline \multirow[t]{2}{*}{ Variable } & \multicolumn{2}{|c|}{ Suicide ideation } \\
\hline & No (\%) & Yes (\%) \\
\hline \multicolumn{3}{|l|}{ Gender } \\
\hline Male & $53(89.8)$ & $6(10.0)$ \\
\hline Female & $32(82.1)$ & $7(17.9)$ \\
\hline \multicolumn{3}{|l|}{ Age } \\
\hline$<40$ & 44 (86.3) & $7(13.7)$ \\
\hline$\geq 40$ & $41(87.2)$ & $6(12.8)$ \\
\hline \multicolumn{3}{|c|}{ Frequency of epileptic seizures } \\
\hline$<6$ & $61(87.1)$ & $9(12.9)$ \\
\hline$\geq 6$ & $25(86.2)$ & $4(13.8)$ \\
\hline \multicolumn{3}{|c|}{ Number of AEDs } \\
\hline$<2$ & $42(89.4)$ & $5(10.6)$ \\
\hline$\geq 2$ & 44 (86.3) & $7(13.7)$ \\
\hline \multicolumn{3}{|l|}{ Depression } \\
\hline$<12$ & $61(100)$ & $0(0.0)$ \\
\hline$\geq 12$ & $24(64.9)$ & $13(35.1)$ \\
\hline \multicolumn{3}{|l|}{ Anxiety } \\
\hline$<10$ & $51(97.8)$ & $1(2.2)$ \\
\hline$\geq 10$ & $34(73.9)$ & $12(26.1)$ \\
\hline
\end{tabular}

AEDs: antiepileptic drugs. Number of occurrences divided by group and percentages regarding each variable factor.

depression (measured by BDI) presented significant differences $(p<0.05)$, and those results will be discussed below.

Table 3 depicts the results of a stepwise discriminant analysis based on the independent variable groups defined as "suicidal ideators" and "non-ideators". The BDI total score without item $9^{18}$, which was used to define the

Table 2. Comparisons between the means for epilepsy, sleep, depression and anxiety by the presence or absence of suicide ideation.

\begin{tabular}{|c|c|c|c|}
\hline $\begin{array}{l}\text { Clinical } \\
\text { variable }\end{array}$ & $\begin{array}{l}\text { Patients with } \\
\text { suicide ideation } \\
{[(n=13) M(S D)]}\end{array}$ & $\begin{array}{l}\text { Patients without } \\
\text { suicide ideation } \\
{[(n=86) M(S D)]}\end{array}$ & $\begin{array}{l}\text { p-value } \\
\text { (U-test*) }\end{array}$ \\
\hline Age & $38.4(10.9)$ & $40.0(12.5)$ & 0.57 \\
\hline $\begin{array}{l}\text { Frequency of } \\
\text { epileptic seizures }\end{array}$ & 35.9 (100.1) & $14.4(44.8)$ & 0.23 \\
\hline Number of AEDs & $1.7(0.6)$ & $1.6(0.7)$ & 0.68 \\
\hline ESS & $10.5(7.3)$ & $9.6(5.2)$ & 0.71 \\
\hline \multicolumn{4}{|l|}{ PSQI } \\
\hline Sleep quality & $2.0(0.8)$ & $1.1(0.8)$ & 0.001 \\
\hline Sleep latency & $1.6(1.0)$ & $1.1(1.1)$ & 0.09 \\
\hline Sleep duration & $1.1(1.3)$ & $0.7(0.9)$ & 0.25 \\
\hline $\begin{array}{l}\text { Habitual sleep } \\
\text { efficiency }\end{array}$ & $0.6(1.1)$ & $0.3(0.8)$ & 0.27 \\
\hline $\begin{array}{l}\text { Sleep } \\
\text { disturbance }\end{array}$ & $1.9(0.7)$ & $1.4(0.7)$ & 0.001 \\
\hline $\begin{array}{l}\text { Use of sleep } \\
\text { medication }\end{array}$ & $0.9(1.3)$ & $0.6(1.2)$ & 0.43 \\
\hline $\begin{array}{l}\text { Diurnal } \\
\text { dysfunction }\end{array}$ & $1.5(0.9)$ & $0.9(0.9)$ & 0.12 \\
\hline Global score & $9.5(4.8)$ & $6.2(4.1)$ & 0.005 \\
\hline $\mathrm{BDI}$ & $25.0(10.6)$ & $10.5(10.2)$ & 0.001 \\
\hline BAl & $32.8(8.0)$ & $8.8(8.3)$ & 0.002 \\
\hline
\end{tabular}

AEDs: antiepileptic drugs; BAl: Beck Anxiety Inventory; BDI: Beck Depression Inventory; ESS: Epworth Sleepiness Scale; PSQI: Pittsburg Sleep Quality Index. *Mann-Whitney-Wilcoxon's $U$ test for independent samples; Statistically significant differences for $p<0.05$. 
Table 3. Discriminant function by the stepwise method for the suicide ideation index.

\begin{tabular}{lcccc}
\hline Variable & Standardized coefficients & Wilk's $\lambda$ & $\mathrm{F}$ & $\mathrm{p}$ \\
\hline BDI (without item 9) & 0.48 & 0.50 & 94.58 & $<0.001$ \\
PSQI - global score & 0.29 & 0.46 & 68.76 & $<0.001$ \\
\hline
\end{tabular}

Epworth Sleepiness Scale; PSQI: Pittsburgh Sleep Quality Index (global score); BDI: Beck Depression Inventory (without item 9) and the Beck Anxiety Inventory. Note: Discriminant analysis between patients with and without suicide ideation by the stepwise method using as function entry variables: frequency of epileptic seizures, number of antiepileptic drugs taken by the patient.

independent variable criterion, was detected as a good predictor of suicidal ideation. The significance of Fisher's ANOVA test was $<0.05$ and Wilk's $\lambda$ and the standardized coefficient described 0.50 and 0.48 of the variables, respectively, indicating that almost half of the sample's covariance was explained by the depression symptoms measured by the BDI. The PSQI (Global score) was also considered a predictor of suicidal ideation, showing a significance of Fisher's ANOVA test of $<0.05$. In this case Wilk's $\lambda$ and the standardized coefficient described 0.46 and 0.29 of the variables, respectively. Other variables did not present significant differences between the two groups and did not contribute to the prediction of the probability of a person belonging to either group.

\section{DISCUSSION}

Our results revealed an association between suicide ideation and depression, anxiety, and sleep. Suicidal ideation affected about $13.3 \%$ of our sample, which is within the range reported by other studies of the general population by Casey et $a{ }^{4}$, who used similar methodology (1.1 to 19.8\%). We identified 10 cases with passive suicidal ideation and 3 cases with active suicidal ideation. Smith et al. ${ }^{18}$ found a low frequency of active suicidal ideation in subjects with chronic pain. It seems that active suicidal ideation may be more strongly related to clinical depression, and passive ideation is more related to pain and sleep disturbances than to depression itself ${ }^{18}$. Sleep disturbance has also been reported as an important predictor of passive suicidal ideation in the psychiatric literature ${ }^{22,23}$.

The presence of anxiety and depression was a risk factor for the occurrence of suicidal ideation among the studied patients, and has been found in several studies ${ }^{1,2,3,6,7,8,9}$. The "suicidal ideators" had the worst rates for quality of sleep (PSQI), sleep alterations (PSQI), global score (PSQI), anxiety (BAI), and depression (BDI), which allows us to suggest a strong association between anxiety and depression and sleep. Several studies have identified important relationships between sleep disorders, depression, suicidal ideation, and suicide $^{10,11,12,13,14,15}$. Bernert and Joiner ${ }^{13}$ observed that higher depression levels largely explained the relationship between sleep disorders and suicide. In our study, it was not possible to determine a cause-and-effect relationship because of the cross-sectional design. Considering the studied demographic and clinical variables, we found no significant results relating age, seizure frequency, or number of AEDs used and the presence or absence of suicidal ideation. The study of Mula et al. ${ }^{24}$, based on only four patients, also failed to show significant results regarding clinical variables.

We observed that depression, BDI total score without item $9^{18}$, and sleep quality (PSQI, global score) were the only variables able to significantly separate "suicidal ideators" and "non-ideators". None of the other studied variables were able to predict this dichotomy in the analyzed sample of this study. Therefore, we suggest that the BDI and PSQI values are good indicators for predicting suicidal ideation among PWE, with the PSQI showing less predictive value. In conclusion, our most important findings were: a) the total BDI score without item $9^{18}$ was the strongest and most statistically significant predictor of suicidal ideation ${ }^{2}$; b) the PSQI (global score) was also predictive of suicidal ideation; c) the PSQI (quality of sleep, sleep disturbances and global score), besides depression and anxiety (Beck scales), showed a significant relationship with suicidal ideation; and d) anxiety was shown to have an important influence with regard to quality sleep and daytime sleepiness (PSQI-global score and ESS, respectively), although this correlation was the weakest. Psychiatric comorbidity has been identified as the primary risk factor for suicide, and depression has been regarded as the most prevalent psychiatric comorbidity in epilepsy, reaching up to $51.7 \%$ in a sample of individuals presenting suicidal thoughts throughout life ${ }^{7}$. Moreover, we observed a strong association between the three variables of the PSQI/quality of sleep, depression, and anxiety in the "suicidal ideators" group, which leads us to infer that suicidal thoughts may be accompanied by sleep disturbances, anxiety, and depression in PWE, increasing the risk of suicide.

The present study suffered some limitations. The number of subjects with suicidal ideation $(n=13)$ may have affected the significance level of some of the clinical and demographic variables within the group containing "suicidal ideators". Another issue was the sample population itself: this was derived from a single university health-care unit, which may have influenced the frequency type in this service. However, this seems to be a methodological problem that is difficult to control. Another issue was with regard to how the data were collected. We were unable to establish schooling in "years", which compromised the inferential 
analysis that included this variable. Although item 9 is known as a fast and effective measure of ideation ${ }^{6}$, the Ideation Beck Inventory could perhaps better inform us on issues regarding the risks of suicidal ideation and suicide. Further investigations using larger samples may result in a higher suicidal ideation, eliminating any doubts about the relationship that some sets of variables established with regard to suicidal ideation in epilepsy. Despite its limitations, we consider this study to be the first to relate sleep and its components with depression and anxiety in a group of PWE with suicidal ideation. As already observed in other studies, we found that depression and anxiety are prevalent com- orbidities in epilepsy ${ }^{1,7,8,9,25}$. Here, we observed that both comorbidities were associated with quality of sleep, daytime sleepiness, and suicidal ideation (predominantly passive). Furthermore, our results revealed that depression (measured by the BDI) and sleep quality (as measured by the PSQI) were good predictors of suicidality in epilepsy. Considering these data, and recognizing that mood disorders ${ }^{7}$ and sleep ${ }^{10,11,12,13,14}$ are important risk factors for suicidal ideation and behavior, we recommend that the study and monitoring of these changes should be prioritized in the treatment of epilepsy, especially in cases of pharmaco-resistant epilepsy and/or psychiatric comorbidities.

\section{References}

1. Tellez-Zenteno JF, Patten SB, Jette N, Williiams J, Wiebe S. Psychiatric comorbidity in epilepsy: a population-based analysis. Epilepsia 2007:48:2336-2344.

2. Lim HW, Song HS, Hwang YH, et al. Predictors of suicidal ideation in people with epilepsy living in Korea. J Clin Neurol 2010;6:81-88.

3. Blumer D, Montouris G, Davies K, Wyler A, Phillips B, Hermann B. Suicide in epilepsy: psychopathology, pathogenesis and prevention. Epilepsy Behav 2002;3:232-241.

4. Casey P, Dunn G, Kelly BD, Lehtinen V, Dalgard OS, Dowrick C, AyusoMateos LJ. The prevalence of suicidal ideation in the general population: results from the outcome of depression international network (ODIN) study. Soc Psych Psychiatr Epidemiol 2008;43:299-304.

5. Botega NJ, Barros MB, Oliveira HB, Delgalarrondo P, Marín-Léon L. Suicidal behavior in the community: prevalence and factors associated with suicidal ideation. Rev Bras Psiquiatr 2005;27:45-53.

6. Verrotti A, Cicconetti A, Scorrano B, Berardis DD, Cotellessa C, Chiarelli F, Ferro FM. Epilepsy and suicide: pathogenesis, risk factors, and prevention. Neuropsychiatric Dis Treat 2008;4:365-370.

7. Jones JE, Hermann BP, Barry JJ, Gilliam FG, Kanner AM, Meador KJ. Rates and risk factors for suicide, suicidal ideation, and suicide attempts in chronic epilepsy. Epilepsy Behav 2003;4(Suppl 3):S31-S38.

8. Pompili M, Girardi P, Ruberto A, Tatarelli, R. Suicide in the epilepsies: a meta-analytic investigation of 29 cohorts. Epilepsy Behav 2005;7:305-310.

9. Stefanello S, Marín-Léon L, Fernandes PT, Li LM, Botega NJ. Psychiatric comorbidity and suicidal behavior in epilepsy: a community-based case-control study. Epilepsia 2010;51:1120-1125.

10. Bernert RA, Joiner TE, Cukrowicz KC. Suicidality and sleep disturbances. Sleep 2005; 28:1135-1141.

11. Agargün MY, Cartwright R. REM sleep, dream variables and suicidality in depressed patients. Psychiatry Res 2003;119:33-39.

12. Chellappa SL, Araujo JF. Sleep disorders and suicidal ideation in patients with depressive disorder. Psychiatry Res 2007;153:131-136.
13. Bernert RA, Joiner TE. Sleep disturbances and suicide risk: a review of the literature. Neuropsychiatr Dis Treat 2007;3:735-743.

14. Agargun MY, Besiroglu L, Cilli AS, Gulec M, Aydin A, Inci R, Selvi Y. Nightmares, suicide attempts and melancholic features in patients with unipolar major depression. J Affect Disord 2007;98:267-270.

15. Krakow B, Ribeiro JD, Ulibarri VA, Krokow J, Joiner TE Jr. Sleep disturbances and suicidal ideation in sleep medical center patients. $\mathrm{J}$ Affect Disord 2011;131:422-427.

16. Buysse DJ, Reynolds CF $3^{\text {rd }}$, Monk TH, Berman SR, Kupfer DJ. The Pittsburgh Sleep Quality Index: a new instrument for psychiatric practice and research. Psychiatry Res 1989;8:193-213.

17. Godoy DV, Godoy RF, Vaccari PT, Michelli M, Teixeira PJZ, Palomini BC. Reduction on the levels of anxiety and depression of COPD patients participating in a pulmonary rehabilitation program. J Pneumol 2002;28:120-124.

18. Smith MT, Perlis ML, Haythornthwaite JA. Suicidal ideation in outpatients with chronic musculoskeletal pain. Clin $J$ Pain 2004;20:111-118.

19. Fisher BJ, Haythornthwaite JA, Heinberg LJ. Clark M, Reed J. Suicidal intent in patients with chronic pain. Pain 2001;89:199-206.

20. Johns MS. A new method for measuring daytime sleepiness: the Epworth sleepiness scale. Sleep 1991;14:504-545.

21. Johnson RA, Wichern DW. Applied multivariate statistical analysis. $4^{\text {th }}$ Edition. New Jersey: Prentice-Hall, 1999

22. Agargun MY, Kara H, Solmaz M. Sleep disturbances and suicidal behavior in patients with major depression. J Clin Psychiatry 1997;58:249-251.

23. Agargun MY, Kara H, Solmaz M. Subjective sleep quality and suicidality in patients with major depression. J Psychiatr Res 1997;31:377-381.

24. Mula M, Sander JW. Suicidal ideation in epilepsy and levetiracetam therapy. Epilepsy Behav 2007;11:130-132.

25. Gomes MM. Epidemiological issues of the psychiatric comorbidities in epilepsy. J Epilepsy Clin Neurophysiol 2008;14:162-170. 